\title{
SCREW TECHNIQUE OUTCOMES; BURST FRACTURES OF LUMBER REGION AND POSTERIOR PEDICLE
}

1. Assistant Professor Neurosurgery Department, Sh. Zayed Hospital, Rahim Yar Khan, Pakistan

2. Medical Officer Sh. Zayed Hospital, Rahim Yar Khan, Pakistan

3. Medical Officer

Neurosurgery Department, Sh. Zayed Hospital,

Rahim Yar Khan, Pakistan

\section{Correspondence Address:} Dr. Muhammad Sohaib Anwer Assistant Professor

Neurosurgery Department Sh. Zayed Hospital,

Rahim Yar Khan, Pakistan.

Article received on: 30/01/2017

Accepted for publication: 20/03/2017

Received after proof reading: 06/05/2017

\section{Dr. Muhammad Sohaib Anwer', Dr. Muhammad Ali², Dr. Moniba Irfan ${ }^{3}$}

ABSTRACT: Objective: The objective of this research was to study a selected population of patients closely and carefully who have lumbar burst fractures and were cured with pedicle screw fixation method. The objective of this study was to judge this technique through surgical results, radiographic outcomes and secondary disease complicacy for the period of surgery and after it. Setting: Neurosurgery departments in Nishtar Hospital, Multan and SH. zayed Hospital, Rahim Yar Khan. Period: December 2013 to August 2016. Study Design: Descriptive Case Series. Methods: Group of 100 successional patients who were operated through posterior arrangement through a posterior pedicle Screw Fixation technique. In this sample of population, 71 men and 29 women were selected; the average age of sample population was 36 years. From this study, the Patients having osteoporotic, delayed vertebral body collapse were left out. The average study duration of these patients was 30 months. Examination of Surgery effects like operation duration, loss of blood and sagittal position was done. Neurological valuation was done via an evaluation scheme basing on "the American Spine Injury Association impairment scale". The study examined inter-body fusion by the use of CT scans and simple X-ray. Results: The average duration of operation was recorded as 255.6 minutes and the average blood loss was recorded as $885.4 \mathrm{ml}$. $64 / 86$, i.e. 64 out of 86 patients having neurological injury $(74.41 \%)$ recuperated functioning after surgery. The numbers of Methodological failure were recorded at a smaller scale of $11 \%$ and rate of fusion, following surgical operation reached the level of $89 \%$. Conclusions: Due to posterior pedicle screws fixation, surgeons have accomplished short segment fixation which could become a beneficial apparatus for fixing lumbar burst fractures.

Key words: Posterior instrumentation; Surgical outcomes; Lumbar burst fractures; Prospective study.

Article Citation: Anwer MS, Ali M, Irfan M. Screw technique outcomes; burst fractures of lumber region and posterior pedicle. Professional Med J 2017;24(5):717-722. DOI: $10.17957 / T P M J / 17.3856$

\section{INTRODUCTION}

In 1986 Denis depicted spinal sagittal profile by categorizing as middle column, anterior and posterior columns. Mechanical stability is greater in middle column due toits position in the spine's neutral axis. Therefore, it assists surgeons to distinguish the burst fractures from compression fractures. Middle columns are affected in burst fractures whereas compression fractures affect only anterior columns. $90 \%$ of the spinal injuries consist of the injuries of the thoracolumbar region and lumbar. Among the injuries of thoracolumbar region and lumbar, about $10 \%$ to $20 \%$ are burst fractures. Neurologic complication and Kyphosis deformity may occur because of the spinal burst fractures that could eventually have a large effect on life of the patients. ${ }^{1-27,28}$
The choice to adopt a suitable surgical procedure for the injured persons is primarilyreliant on, experience of the surgeons, pattern of the fractures, and extent of neurological injury.

Among medical practitioners there are numerous debates regarding the best methodologies for treatment of such types of the lumbar spine fractures. However, doctors have reached on an agreement that the surgery is the best cure, necessary to cope with these uneven lumbar burst fractures.

Recently, due to a great deal of improvements in backbone surgery and hardware techniques, plenty of choices are available for surgeons who are aiming at instrumentation and operating 
methods. ${ }^{3-8}$

For the treatment of burst fractures, the vastly utilized methodologies are as follows; anterior decompression, posterior pedicle screw fixation, reconstruction method, and combined anterior posterior scheme. Each schema has its own merits and demerits. ${ }^{9,10}$ However as a reality, there is no flawless surgical technique available to handle such fractures till today.

Even though anterior approach unwinds the nerves and is capable of providing a reliable reinforcement to the frontal column. But this technique is not much effective due to the extended average operating time, rate of complications (approach related) is higher and the higher death rate vis-a-vis posterior technique.

Though the combined posterior anterior technique has been proved as the best stable repair procedure however, some demerits are associated to it as well. e.g. great time-consuming surgery, mortality rate is higher and numerous complications attached with this combined methodology, in comparison with the single approach.

So conventionally for the treatment of burst fractures, posterior approach is easier. ${ }^{11,12,13,14,15}$

The posterior approach can be categorized into long segment fixation, mono segment fixation, and short segment fixation. Presently, short segment pedicle screw arrangement is quite common technique as a choice for reduction and alleviation of the lumbar spine fractures. ${ }^{15}$

Formerly, studies have proved the technique of managing burst fracture in lumber spine region through posterior approach as technically easy and operative methodology.Nevertheless, there are some limitations due to the short time span of follow up in the fractures in which successful healing is proved and complications are avoided. This study was performed to appraise the practical results of the aforementioned technique after surgical intervention for the period oftwelve to fourteen months.
OBJECTIVE

To examine the medical results of posterior pedicle Screw Fixation technique for the treatment of lumbar spine fractures in a span of twelve to fourteen months of post-surgical intervention.

\section{METHOD AND MATERIAL}

This study is a description of cases series that was conducted at the "Neurosurgery departments in Nishtar Hospital, Multan and SH. zayed Hospital, Rahim Yar Khan" during December 2013 to August 2016. Sample of the population (patients) was selected through purposive non probability sampling. Patients were educated by describing the objective of this study to them before their participation, and verbal consent was taken from all the patients who were considered for the study. Thorough secrecy was ensured for the information of this study. Next to maintaining patients' record, like, clinical examinations, investigations like X-rays, CT scans, MRI, the complete medical history, their results, and such facts were recorded under the direction of expert neurosurgeon. Nevertheless, the patients having history of lungs surgery were not selected for this procedure. Similarly, the patients who were under severe abdominal aortic aneurysms or pulmonary dysfunction were not chosen for this study. Besides, severity of fracture, its cause, Blood loss in operating it, average surgery time, infection by neurosurgeon, perioperative complications in shape of hard-ware failure, advancement in power and postoperative state of leaning / reclining period were investigated. Neurological appraisal was carried out on every patient by a particularly developed ranking system, on the basis of "American Spine Injury Association impairment scale".

The posterior fixation through a pedicle screw was conducted .X-ray was done for checking the fractures. Additionally, for every patient a precise diagnosis of injury to the vertebra was ensured through Tomography and MRI.

\section{RESULTS}

All the patients went through a pediclescrew fixation through posterior instrumentation by the means of pedicle screws, rods and hooks. A 
total of 100 patients were kept under observation for this procedure. Among those 100 patients, 71 were males and 29 were females. At the time of surgery, the average age of the patients was 12.5 \pm 4 years (range 15-79). Distribution of the selected sample of gender population is described as age-wise, in the table given below.

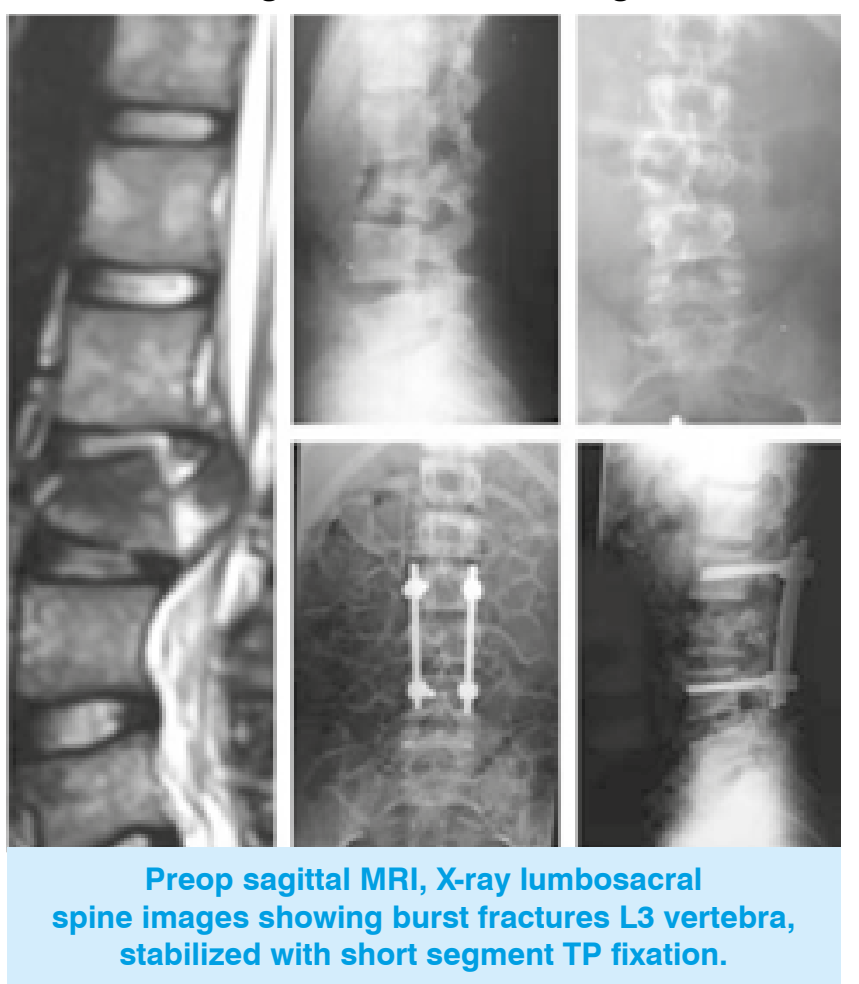

\begin{tabular}{|l|c|c|c|}
\hline $\begin{array}{c}\text { Age Groups } \\
\text { (In Years) }\end{array}$ & $\begin{array}{c}\text { Male } \\
(\mathbf{n = 7 1 )}\end{array}$ & $\begin{array}{c}\text { Female } \\
(\mathbf{n = 2 9 )}\end{array}$ & P-value \\
\hline $21-30$ & 22 & 20 & \\
\hline $31-40$ & 19 & 5 & \multirow{2}{*}{0.002} \\
\hline $41-50$ & 26 & 4 & \\
\hline $51-80$ & 4 & 0 & \\
\hline Total & \multicolumn{3}{|c|}{100} \\
\hline Table-I. Age group Cross-tabularization w.r.t the \\
Gender
\end{tabular}

The average surgery time was calculated as $255.6 \pm 50.3 \mathrm{~min}$ and average $885.4 \pm 726.1 \mathrm{ml}$ of blood loss was observed. The average postoperation recumbence time was $2.8 \pm 1.5$ days. The average post-operation follow-up time was calculated as $13.4 \pm 2.5$ months.
Also, major reasons of fractures were worked out through observation, and these were documented in the datasheet. Following facts show main reasons of fractures and their frequency in patients under observation. From the total 100 patients, $65 \times$ patients injured by falling from higher places/ positions, and $17 \times$ patients injured by the hit of vehicles in road accidents. $10 x$ patients were injured due to blunt contusion with weighty falling bodies. Four patients got injured by sledding accident andthe rest of four patients injured during sports accidents.

Post-surgery management and improvement instrength was observed in $75(75.0 \%)$ of the cases under study. Moreover, there was 11.0 $\%$ hardware failure and $14 \mathrm{x}$ patients $(14.04 \%)$ suffered from infection.

\begin{tabular}{|l|c|c|c|}
\hline \multirow{2}{*}{$\begin{array}{c}\text { Improvement } \\
\text { in Power }\end{array}$} & $\begin{array}{c}|c| \\
\text { Male } \\
(\mathbf{n = 7 1 )}\end{array}$ & $\begin{array}{c}\text { Female } \\
(\mathbf{n = 2 9 )}\end{array}$ & P-value \\
\hline Yes & 65 & 10 & \multirow{2}{*}{0.021} \\
\hline No & 6 & 19 & \\
\hline
\end{tabular}

Table-II. Improvement in power Cross-tabularization w.r.t. Gender

\begin{tabular}{|l|c|c|c|}
\hline \multirow{2}{*}{$\begin{array}{c}\text { Hardware } \\
\text { Failure }\end{array}$} & \multicolumn{2}{|c|}{ Gender } & Male \\
$(\mathbf{n = 7 1 )}$ & Female & P-value \\
\hline Yes & 5 & 6 & 0.74 \\
\hline No & 66 & 23 & \\
\hline
\end{tabular}

Table-III. Hardware Failure Cross-tabularization w.r.t. Gender

\begin{tabular}{|l|c|c|c|}
\hline \multirow{2}{*}{ Infection Caused } & \multicolumn{2}{|c|}{ Gender } & \multirow{2}{*}{ P-value } \\
\cline { 2 - 3 } & Male & Female & \\
\hline Yes & 09 & 05 & 0.478 \\
\hline No & 62 & 24 & \\
\hline
\end{tabular}

Table-IV. Infection Cross-tabulation w.r.t. Gender

\section{DISCUSSION}

There has been a lot of debate on management of lumbarspine burst fractures, and quite a fewcontroversies are found in literature related to this procedure. The major objectives of surgery for injury related management consist ofadjustment 
of the deformity, restraining progression of deformity, lessening of neurologic deficit by the stabilization of the fracture. This may eventually end into a reduced stretch of rehabilitation.

Neurologic complication and Kyphosis deformity may occur regarding burst fractures of lumbar spine that eventually might have huge impact on life of an injured person. ${ }^{24-26}$ More than a few controversies are found amongst the medical specialists on the subject of the best procedures for treatment of the lumbar spine fractures. Conversely, a common agreement has been reached among the medical practitioners that surgery is the best cure necessary for managing unstable lumbar burst fractures.

Presently, doctors have so many choices of instrumentation and surgical techniques asa lot of developments have been made and are being made in spine surgery and hardware techniques. ${ }^{19,26}$

The mostly used and vastly implemented procedures for the treatment of burst fracturesare; anterior decompression \& reconstruction approach, posterior pedicle screw fixation method, and combined anterior posterior methodology. Every technique has its own merits and demerits. ${ }^{4,13}$ Nonetheless, it is also a fact that no perfect surgical technique could have been found till today.

Even though anterior approach adequately and effectively opens the nerves and through this technique surgeons are able to deliver reliable support to the anterior column, yet this method is not much effective due to extended mean surgery time, higher rate of correlated complications and significant death rate vis-à-vis posterior approach.

While the anterior posterior combined methodology has been demonstrated as most stead fast patch-up procedure but it also has some disadvantages e.g. a large number of complications related to this combined technique, longer operation mean time and higher mortality rate, as contrasted to the single technique methods. Conventionally posterior methodology is much easier for managing burst fractures.

We can further divide the posterior approach into mono-segment fixation, short-segment fixation and long-segment fixation. At present, short- segment pedicle screw arrangement has become a technique of choice in reducing and stabilizing the lumbar spine fractures. ${ }^{18}$ Aebi, Ether, Dickson, Kohl, Blauth, Jacobs, and Farcy et al. professed pedicle screw fixation as the basic cure for managing and stabilizing burst fractures. ${ }^{16,17,18,19,20}$ Coster et al. conducted a clinical appraisal amongst sublaminar wires, luque rods, hooks, Harrington rod and pedicle screws with a population of 70 patients and presented an analysis report that pedicle screw fixation can be used for small segments and it provided greater stability in comparison with the posterior fixation apparatuses. ${ }^{21}$ James, Hak, Kim, Allen, and Chung et al. affirmed that pedicle screw fixation is a better technique for lumbar burst fractures. ${ }^{22-23}$

The actual advantage of this approach is the easiness and familiarity it offers to the surgeons and revitalizing (presuming) the motion segment. Nonetheless, refurbishing the anterior column is quite difficult that may lead to acute pain, unstableness and neurologic deficit. ${ }^{24,22}$

Since, there is no diaphragm dissection in such extra pleural techniques of treatment; therefore, the postoperative complications are uncommon. Generally, the options of stabilizing these fractures are posterior or anterior fusion. For restoration of spinal stability, the Posterior spinal surgery is now a very popular method. ${ }^{14,15,16}$ It has also been reported through various cases of surgery, that because of bone breakdown, sagittal plane kyphosis was found irredeemable in lumbar fractures. ${ }^{20}$ Nonetheless, this study has revealed satisfactory results in restoration. Various intellectuals have reported that the occurrence ratio of lumber fractures is lesser in female patients. Similarly, thefindings of our research have also revealed the same phenomenon because $71 \%$ male patients were affected by 
lumber fractures as compared to that of $29 \%$ comprising of female patients. Erozlu, Ozturk, and Aydinili also discussed the resembling results in their research for lumbar spine burst fractures and theaverage age of observed population was $12.5 \pm 4$ years (Range_UL15-LL79). Rehman et al. stated the average age that was analogous to our research. Lumbar burst fractures are usually witnessed in young people because of falling from elevated positions, accidents by the strike of some vehicles. Khan et al. has also worked on fractures in young people. They showedtheir discoveries by recording $40 \pm 13.75$ years as average age of patients. By achieving stability restoration through the three spinal columns, the posterior methodology balances the deficiencies of anterior setup. Moreover, surgery time duration and loss of blood in these operations was lesser than those of the other studies conducted elsewhere. This surgery approach succeeded in achieving higher union ratio and lowerrate of flop in instrumentation. Previously, studies revealed $12-19 \%$ rate of contamination/ infection however in this research study the rate was lesser i.e. $11 \%$.

\section{CONCLUSION}

The research study findings have revealed that the posterior techniquewhich is comprised of a posterior fixation with a pedicle screw and hook system, is safer \& operative method which provide spinal stability efficiently. This apparatus have benefits like minimal amount of blood loss, and minimum trauma and it leads to quick recovery and restoration of mobility of the patient. Physiotherapy is easier in this technique. Besides, this technique is practical and useful choice because neurological recovery and pain control is better than those in the rest of the techniques. Copyright@ 20 Mar, 2017.

\section{REFERENCES}

1. Denis $F$ : The three column spine and its significance in the classification of acute thoracolumbar spinal injuries. Spine. 1983, 8: 817-831. 10.1097/00007632198311000-00003. View ArticlePubMedGoogle Scholar

2. Frankel HL, Hancock DO, Hyslop G, et al: The value of postural reduction in the initial management of closed injuries of the spine with paraplegia and tetraplegia. Paraplegia. 1969, 7: 179-192. 10.1038/
sc.1969.30.View ArticlePubMedGoogle Scholar.

3. McCormack T, Kariokovic E, Gaines RW: The load sharing classification of spine fractures. Spine. 1994, 19: 1741-1744. 10.1097/00007632-199408000-00014. View ArticlePubMedGoogle Scholar.

4. Kaneda K, Taneichi H, Abumi K, et al: Anterior decompression and stabilization with the Kaneda device for thoracolumbar burst fractures associated with neurological deficits. J Bone Joint Surg Am. 1997, 79: 69-83.PubMedGoogle Scholar.

5. Sasso RC, Best NM, Reilly TM, et al: Anterior-only stabilization of three column thoracolumbar injuries. J Spinal Disord Tech. 2005, 18 (suppl): S7-S14.View ArticlePubMedGoogle Scholar.

6. Alanay A, Acarolu E, Yazici M, et al: Short-segment pedicle instrumentation of thoracolumbar burst fractures: does transpedicularintracorporeal grafting prevent early failure. Spine. 2001, 26: 213-217. 10.1097/00007632-200101150-00017.View ArticlePubMedGoogle Scholar.

7. Alvine GF, Swain JM, Asher MA, et al: Treatment of thoracolumbar burst fractures with variable screw placement or Isola instrumentation and arthrodesis: case series and literature review. J Spinal Disord Tech. 2004, 17: 251-264. 10.1097/01. bsd.0000095827.98982.88.View ArticlePubMedGoogle Scholar.

8. Ramani PS, Singhania BK, Murthy G: Combined anterior and posterior decompression and short segment fixation for unstable burst fractures in the dorsolumbar region. Neurol India. 2002, 50 (3): 272278.PubMedGoogle Scholar.

9. Gurwitz GS, Dawson JM, McNamara MJ, et al: Biomechanical analysis of three surgical approaches for lumbar burst fractures using short-segment instrumentation. Spine. 1993, 18: 977-982. 10.1097/00007632-199306150-00005.View ArticlePubMedGoogle Scholar.

10. Been HD, Bouma GJ: Comparison of two types of surgery for thoraco-lumbar burst fractures: combined anterior and posterior stabilization vs. Posterior instrumentation only. ActaNeurochir (Wien). 1999, 141: 349-357. 10.1007/s007010050310.View ArticleGoogle Scholar.

11. Hitchon PW, Torner J, Eichholz KM, et al: Comparison of anterolateral and posterior approaches in the management of thoracolumbar burst fractures. J Neurosurg Spine. 2006, 5 (2): 117-125. 10.3171/ spi.2006.5.2.117.View ArticlePubMedGoogle Scholar.

12. Knop C, Fabian HF, Bastian L, Blauth M: Late 
results of thoracolumbar fractures after posterior instrumentation and transpedicular bone grafting. Spine. 2001, 26: 88-99. 10.1097/00007632-20010101000016. View ArticlePubMedGoogle Scholar.

13. Andress $\mathrm{HJ}$, Braun $\mathrm{H}$, Helmberger $\mathrm{T}$, et al: Long-term results after posterior fixation of thoraco-lumbar burst fractures. Injury. 2002, 33: 357-365. 10.1016/ S0020-1383(02)00030-X.View ArticlePubMedGoogle Scholar.

14. Gelb D, Ludwig S, Karp JE, et al: Successful treatment of thoracolumbar fractures with short-segment pedicle instrumentation. J Spinal Disord Tech. 2010, 23 (5): 293-301. 10.1097/BSD.0b013e3181af20b6.View ArticlePubMedGoogle Scholar.

15. Aebi M, Etter C, Kehl T. Stabilization of the lower thoracic and lumbar spine the internal spine skeletal fixation system.Indication, technique, and first results of treatment. Spine1987; 12:544-51.

16. Dickson JH, Harrington PR, Erwin WD. Results of reduction and stabilization of the severely fractured thoracic and lumbar spine. J Bone Joint Surg1978; 60:799-805.

17. Jacobs RR, Casey MP. Surgical management of thoracolumbar spinal injuries. ClinOrthopRelat Res1984; 189:22-35.

18. Sar C, Bilen FE. Flexion was more painful than extension. Thoracolumbar flexion-distraction injuries combined with vertebral body fractures. Am J Orthop 2002; 31:147-51.

19. Blauth M, TscherneM: Theraputic concept and results of operative treatment in acute trauma of the thoracic and lumbar spine: The Hanover experience. J Orthop
Trauma 1987; 1:240-52.

20. Farcy JP, Veidenbaum M, Glassman S. Sagittal index in management of thoracolumbar burst fractures. Spine 1990; 15:958-65.

21. Sasso RC, CostlerHB: Posterior Instrumentation and fusion for unstable fractures and fracturedislocations of the thoracic and lumbar spine. Spine 1993; 18:450-60.

22. James JY, Allen S, Christopher S, Lawrence S, Kenneth W,Mark T, et al. The Treatment of Unstable Thoracic Spine Fractures with Transpedicular Screw Instrumentation: A 3-Year Consecutive Series. Spine 2002; 27:2782-7.

23. Kim KS, Oh SH, Huh JS, Noh JS, Chung BS. Dorsal Short-Segment Fixation for Unstable Thoracolumbar Junction Fractures. J Korean NeurosurgSoc 2006; 40:249-55.

24. McCormack T, Karaikovic E, Gaines RW. The loadshearing classification of spine fractures. Spine 1994; 19:1741-4.

25. Butler JS, Walsh A, O'Byrne J. Functional outcome of burst fractures of the first lumbar vertebra managed surgically and conservatively. IntOrthop 2005; 29:514.

26. Rahman R, Azmatullah, Azam F, Mushtaq, Shah M. Treatment of unstable thoracolumbar junction fractures with transpedicular screw fixation. $\mathrm{J} P a k$ Med Assoc. 2011; 61:1005-8.

27. Khan AA, Khanzada K, Ayub S, Ali M. Surgical outcome of transpedicular fixation in thoracolumbar fractures. JAyub Med Coll Abbottabad. 2008; 20(4):104-107.

AUTHORSHIP AND CONTRIBUTION DECLARATION

\begin{tabular}{|c|c|c|}
\hline Sr. \# & \multicolumn{1}{|c|}{ Author-s Full Name } & \multicolumn{1}{c|}{ Contribution to the paper } \\
\hline 1 & Dr. Muhammad Sohaib Anwer & $\begin{array}{l}\text { Concept of study, data } \\
\text { collection, data analysis } \\
\text { and manuscript writing } \\
\text { and checking } \\
\text { Data collection, data } \\
\text { analysis and manuscript } \\
\text { writing and checking } \\
\text { Data collection, data } \\
\text { analysis }\end{array}$ \\
\hline 3 & Dr. Muhammad Ali & Dr. Moniba Irfan
\end{tabular}

